\title{
Kualitas Hidup Pada Ibu dari Anak dengan Gangguan Spektrum Autisme
}

\author{
Putri Fitriana Herdani ${ }^{1 凶}$, Fredrick Dermawan Purba $^{2}$, Yuliana Hanami ${ }^{3}$ \\ ${ }^{1,2,3}$ Fakultas Psikologi, Universitas Padjajaran \\ putri19029@mai1.unpad.ac.id
}

\begin{abstract}
Mothers who have children with autism spectrum disorders will confront challenges in the nurturing and treatment of their children compared to mothers in general. This study aims to describe the quality of life of mothers who have children diagnosed with autism spectrum disorders. Seven mothers of children diagnosed with autism spectrum disorders participated. This research employed a phenomenological approached implemented through a qualitative methodology. Participants in this study were seven mothers of children diagnosed with autism spectrum disorders. Data collected through interview. Data was collected during the Covid-19 pandemic so that 3 mothers interviews were conducted online with audio call whatsapp and 4 mothers interviews were conducted offline according to health protocols. The data analysis technique used thematic analysis. The results showed that there were 23 themes that described the quality of life mother of children with autism spectrum disorder which consisted of four domains: physical, psychological, social and environmental. In the physical domain, mothers of children with autism fell physically and psychologically exhausted. In the psychological domain, there are various kinds of feelings that are felt from the beginning of the diagnosis, while treating a child with autism. In the domain of social relations, mothers of children with autism affect relationship with family, friends, neighbors and husbands. With the support provided, mothers feel enthusiastic and grateful in caring for children with autism. In the environmental domain, mothers have needs for the care of children with autism for therapy and school. Mothers can learn new things and able to obtain information from various sources. For mothers, facilities needed for children with autism are considered adequate, starting health facilities, transportation, and physical environmental conditions.
\end{abstract}

Keywords: Quality of Life, Mothers, Autism, Phenomenological Approach, Spectrum Disturbance.

\begin{abstract}
Abstrak
Ibu dari anak dengan gangguan spektrum autisme akan menghadapi tantangan pengasuhan dan perawatan anak mereka dibandingkan dengan ibu pada umumnya. Penelitian ini bertujuan untuk mendeskripsikan kualitas hidup ibu yang memiliki anak dengan diagnosa gangguan spektrum autisme. Partisipan dalam penelitian ini terdiri dari 7 orang yang merupakan ibu dari anak yang didiagnosa gangguan spektrum autisme. Penelitian ini merupakan penelitian kualitatif dengan pendekatan fenomenologi. Data dikumpulkan melalui wawancara. Pengambilan data dilakukan pada masa pandemi Covid-19 sehingga 3 ibu diwawancarai melalui saluran platform audio call whatsapp dan 4 ibu wawancara secara langsung sesuai dengan protokol kesehatan. Teknik analisis data menggunakan tematik analisis. Hasil penelitian menujukkan terdapat 23 tema yang menggambarkan kualitas hidup ibu dari anak dengan gangguan spektrum autisme yang terdiri dari empat domain yaitu, kesehatan fisik, psikologis, relasi sosial dan lingkungan. Pada domain kesehatan fisik, mereka merasakan lelah secara fisik maupun psikis. Pada domain psikologis, terdapat perasaan yang dirasakan saat menerima diagnosa dan selama merawat anak dengan autisme. Pada domain relasi sosial, ibu dari anak dengan autisme berpengaruh terhadap hubungan dengan keluarga, teman, tetangga dan pasangan. Dengan adanya dukungan yang diperoleh ibu merasa semangat dan bersyukur dalam merawat anak dengan autisme. Pada domain lingkungan, ibu memiliki kebutuhan untuk melakukan terapi dan sekolah. Ibu menerima hal-hal baru dan memperoleh informasi mengenai autisme dari berbagai sumber. Bagi ibu, fasilitas yang dibutuhkan anak dengan autisme dirasa sudah cukup memadai dari fasilitas kesehatan, transportasi dan kondisi lingkungan fisik.
\end{abstract}

Kata kunci: Kualitas Hidup, Ibu, Autisme, Pendekatan Fenomenologi, Gangguan Spektrum.

(C) 2022 PSY165 Journal

\section{Pendahuluan}

Gangguan spektrum autisme merupakan suatu neurodevelopmental disorder yang kompleks ditandai dengan adanya defisit dalam komunikasi sosial, menunjukkan tingkah laku yang berulang dan terus menerus, serta minat atau ketertarikan yang tidak fleksibel (kaku) dan menginginkan pola yang sama [1]. Prevalensi gangguan spektrum autisme di seluruh Negara Amerika Serikat dan non-Amerika Serikat telah mendekati $1 \%$ dari populasi dengan perkiraan yang sama pada sampel anak dan dewasa [2].
Berdasarkan Center for Disease Control and Prevention (CDC, 2014), disebutkan bahwa prevalensi kejadian penderita autisme meningkat 1 per 150 populasi pada tahun 2000 menjadi sebesar 1 per 59 pada tahun 2014. Penderita autisme lebih banyak terjadi pada anak laki-laki dengan prevalensi 1:37 sedangkan anak perempuan 2:151 [3].

Pada awal masa perkembangan, anak-anak dengan gangguan spektrum autisme menunjukkan abnormalitas dalam komunikasi dan bahasa [4]. Mereka menampilkan berbagai perilaku terbatas dan 
berulang seperti mengayun atau mengepakkan tangan dan lengan dengan intensitas sedemikian rupa. Anakanak dengan autisme juga menunjukkan karakteristik terkait defisit intelektual, motivasi, serta kondisi medis dan karakteristik fisik [1]. Anak-anak dengan autisme juga dapat mengalami kondisi medis yang mungkin penyebab dalam gangguan mereka [5][6] termasuk gangguan motorik dan sensori, kejang, kelainan imunilogis dan metabolik, serta gangguan tidur.

Selain itu mereka mengalami kesulitan berhubungan dengan orang lain [7]. Anak-anak dengan gangguan spektrum autisme juga sulit dalam memahami informasi dan ekspresi emosi yang mereka rasakan sendiri dan mengenali emosi dari orang lain [8].

Kesulitan yang dialami anak dengan gangguan spektrum autisme tidak hanya mempengaruhi anak tetapi juga orang tua, salah satunya ibu sebagai pengasuh utama yang memainkan peran penting serta berpengaruh dalam perkembangan anak [9]. Ibu akan menghadapi tantangan dalam pengasuhan dan perawatan terhadap anak dengan gangguan spektrum autisme [10]. Ketika ibu pertama kali mengetahui bahwa anaknya didiagnosis gangguan spektrum autisme, mereka akan memperlihatkan berbagai reaksi seperti syok, kecewa, cemas, sedih, malu atau marah. Awalnya mereka tidak percaya dengan diagnosa yang mereka terima [11].

Ibu dari anak dengan gangguan spektrum autisme memerlukan finansial yang cukup untuk memenuhi kebutuhan perawatan yang terdiri dari layanan pendidikan dan kesehatan yang intensif [12][13]. Biaya perawatan anak dengan autisme enam kali lebih besar daripada anak yang berkembang secara normal [14]. Dalam memenuhi kebutuhan anak dengan autisme dengan biaya perawatan yang lebih tinggi dapat menyebabkan ibu mengalami permasalahan keuangan[15][16][17]. Ibu dari anak dengan gangguan spektrum autisme juga akan menghadapi karakteristik dan perilaku dibandingkan anak pada umumnya. Ibu akan menghadapi perilaku anak seperti mengamuk, menunjukkan ketakutan yang ekstrem atau menghindari benda bising atau bergerak [1] atau perilaku tantrum [18]. Ketidakpastian perilaku dan kekhawatiran kondisi anak yang permanen menyebabkan masalah psikologis [17]. Ibu dari anak dengan autisme akan mengalami peningkatan stres [19].

Dalam menghadapi kondisi dan perilaku anak dengan gangguan spektrum autisme, ibu juga membutuhkan banyak waktu, upaya dan kesabaran [12][13]. Pengasuhan dan perawatan yang diberikan kepada anak dengan gangguan spektrum autisme menyebabkan ibu tidak memiliki banyak waktu untuk beristirahat yang dapat mempengaruhi kesehatan fisik seperti sakit kepala, sakit punggung, atau masalah tidur [17]. Anak dengan gangguan spektrum autisme juga membutuhkan perhatian dan pengawasan yang intens sehingga dapat menimbulkan perasaan terisolasi dan frustrasi [17].

Berbagai kondisi yang dialami ibu dalam pengasuhan dan perawatan anak dengan gangguan spektrum autisme dapat menjelaskan bagaimana kualitas hidup yang dimiliki ibu. Berdasarkan World Health Organization (WHO), kualitas hidup didefinisikan sebagai persepsi dan posisi individu dalam kehidupan pada konteks sistem nilai serta budaya mereka tinggal dan berdasarkan kaitannya dengan tujuan hidup masing-masing individu, harapan serta standar yang diterapkannya [20]. Ibu dari anak dengan gangguan spektrum autisme memiliki persepsi mengenai kehidupan mereka dalam pengasuhan dan perawatan anak yang meliputi kesehatan fisik, psikologis, hubungan sosial dan lingkungan. Setiap ibu memiliki kualitas hidup yang berbeda tergantung bagaimana mereka menyikapi kondisi yang terjadi dalam dirinya yaitu mengasuh dan merawat anak dengan gangguan spektrum autisme yang dipengaruhi oleh kesehatan fisik, psikologis, hubungan sosial dan hubungan dengan lingkungan.

Kualitas hidup ibu dikhawatirkan kemampuan dalam memberikan perawatan dan pengasuhan tidak mencapai keoptimalan. Mengingat kebutuhan perawatan dan pengasuhan anak dengan gangguan spektrum autisme serta intervensi yang diberikan membutuhkan keterlibatan seorang ibu. Berdasarkan paparan tersebut, penelitian ini bermaksud untuk memperoleh pandangan ibu dari anak dengan gangguan spektrum autisme mengenai kualitas hidup selama memberikan pengasuhan dan perawatannya.

\section{Metodologi Penelitian}

Metode yang digunakan dalam penelitian ini adalah metode kualitatif dengan pendekatan fenomenologi. Pendekatan fenomenologi merupakan suatu rancangan inkuiri yang bersumber dari filsafat dan psikologi dimana peneliti mendeskripsikan pengalaman hidup individu tentang suatu fenomena seperti yang dijelaskan oleh partisipan [21]. Pada penelitian ini menggambarkan pengalaman ibu sebagai pengasuh dari anak dengan gangguan spektrum autisme memberikan pandangan bagaimana kualitas hidup yang dirasakan secara langsung selama pengasuhan dan perawatan yang diberikan. Kriteria partisipan pada penelitian ini adalah ibu yang memiliki anak dengan gangguan spektrum autisme. Tabel 1 menyajikan gambaran umum partisipan dalam penelitian ini.

Instrumen dalam penelitian ini menggunakan panduan wawancara semi-terstruktur yang disusun berdasarkan teori kerangka domain-domain kualitas hidup oleh WHOQoL Group, 1995. Peneliti menjelaskan tujuan dan prosedur penelitian yang kemudian partisipan diminta mengisi informed consent. Wawancara dilakukan secara individual dimana beberapa partisipan melalui saluran daring whatsapp dan terdapat partisipan yang bersedia wawancara secara 
langsung sesuai protokol kesehatan. Panduan wawancara diformulasikan dengan pertanyaan komunikatif, artinya panduan dikembangkan atau probing tergantung dari respon setiap partisipan namun tetap menyasar pada inti pertanyaan. Panduan wawancara sebelumnya memperoleh umpan balik dari tiga orang ahli untuk meningkatkan keandalan (reliability) dan keterpercayaan (trustworthiness) sebagai instrument penelitian [22]. Gambaran umum partisipan disajikan pada Tabel 1 .
Tabel 1. Gambaran umum partisipan

\begin{tabular}{lcrl}
\hline & Usia & Usia anak & Tingkat keparahan \\
\hline Partisipan 1 & 50 & 14 & Parah-hiperaktif \\
Partisipan 2 & 40 & 10 & PDD Nos \\
Partisipan 3 & 43 & 9 & Ringan \\
Partisipan 4 & 40 & 10 & Ringan \\
Partisipan 5 & 46 & 14 & Sedang \\
Partisipan 6 & 48 & 7 & Ringan \\
Partisipan 7 & 35 & 10 & Sedang \\
\hline
\end{tabular}

\section{Hasil dan Pembahasan}

Berdasarkan hasil temuan penelitian yang dilakukan terhadap subjek penelitian diperoleh kualitas hidup ibu dari anak dengan Gangguan Spektrum Autisme berdasarkan domain-domain WHOQoL Group tahun 1995 yang disajikan pada Tabel 2.

Tabel 2. Hasil Temuan Tema

\begin{tabular}{|c|c|c|}
\hline Domain & Tema & Pernyataan ibu \\
\hline \multirow{8}{*}{ Fisik } & Aktivitas sehari- hari & Alhamdulillah, alhamdulillah masih bisa..bisa \\
\hline & $\begin{array}{l}\text { Kesehatan ibu dari anak dengan } \\
\text { autisme }\end{array}$ & $\begin{array}{l}\text { Apa ya, saya.kayaknya jarang yah, pusing gak pernah amit-amit gitu, pusing } \\
\text { gak pernah. }\end{array}$ \\
\hline & Kemampuan mobilitas & Alhamdulillah ga ada bu \\
\hline & & Pasti cape yah. Karena gini kalau kasarnya haduh ini kok gimana sih gitu \\
\hline & $\begin{array}{l}\text { Rasa lelah dan energi yang } \\
\text { dimiliki }\end{array}$ & $\begin{array}{l}\text { kan cape gitu kan,.karena kan jadi gini mengasuh orang dikasih tau cukup } \\
\text { berkali-kali, kata kita enggak. berbulan-bulan kadang rasa itu tuh jenuh teh } \\
\text { memang jenuh. }\end{array}$ \\
\hline & Rasa sakit secara fisik & $\begin{array}{l}\text { Saya pernah ngerasain itu pegal-pegal gimana tapi kalau sampai pegel-pegel } \\
\text { tiap hari itu enggak sih }\end{array}$ \\
\hline & Tidur dan istirahat & $\begin{array}{l}\text { Saya tetap berusaha kalau misalkan itu cape, siang harus tetap tidur siang di } \\
\text { kamar. }\end{array}$ \\
\hline & $\begin{array}{l}\text { Bekerja atau mengikuti kegiatan } \\
\text { lainnya }\end{array}$ & Jalan-jalan, belanja biasa pergi sama temen. \\
\hline \multirow{5}{*}{ Psikologis } & $\begin{array}{l}\text { Perasaan memiliki anak dengan } \\
\text { autisme }\end{array}$ & $\begin{array}{l}\text { Tapi saya ambil hikmahnya apa, punya anak A ya Allah gak tau hikmah apa } \\
\text { yang diberikan, apa sih bukan pujian tapi Allah terlalu sayang. }\end{array}$ \\
\hline & Merawat diri dan penampilan & Saya masih bisa dandan, masih bisa \\
\hline & Kepercayaan diri & $\begin{array}{l}\text { Iya dan kitanya harus pede, kalau kita nya malu atau apa mah sama orang } \\
\text { diledekin orang kalau istilahnya mah. }\end{array}$ \\
\hline & Spiritualitas dan religiusitas & Saya lebih dekat ya \\
\hline & $\begin{array}{l}\text { Kemampuan berpikir, belajar, } \\
\text { mengingat dan konsentrasi }\end{array}$ & Kalau kesulitan kayaknya enggak deh, alhamdulillah enggak enggak ada. \\
\hline \multirow{4}{*}{$\begin{array}{l}\text { Relasi } \\
\text { sosial }\end{array}$} & $\begin{array}{l}\text { Relasi sosial ibu dari anak } \\
\text { dengan autisme }\end{array}$ & $\begin{array}{l}\text { Ada juga yang gak menerima, ada juga yang menerima tapi saya sih enggak } \\
\text { marah atau apa ya }\end{array}$ \\
\hline & Interaksi di lingkungan sosial & $\begin{array}{l}\text { Perasaan was was bu. Perasaan ini kalau saya lepas bermain di lingkungan } \\
\text { normal. Kalau dengan saya atau papahnya gak teralalu khawatir }\end{array}$ \\
\hline & $\begin{array}{l}\text { Dukungan yang diperoleh ibu } \\
\text { dari anak dengan autisme }\end{array}$ & $\begin{array}{l}\text { Dukungan salah satunya itu keuangan dukung banget, kedua kalau misalkan } \\
\text { ada informasi-informasi tentang terapi atau apa ayo mama ikut aja gapapa } \\
\text { gitu. }\end{array}$ \\
\hline & $\begin{array}{l}\text { Hubungan intim dengan } \\
\text { pasangan }\end{array}$ & $\begin{array}{l}\text { Iya berpengaruh kayak aduh udah cape pasti saya udah kerja maksudnya } \\
\text { sebagai ibu rumah tangga gitu ya, papahnya udah cape di kantor pulang, bibi } \\
\text { pulang. }\end{array}$ \\
\hline \multirow{7}{*}{ Lingkungan } & $\begin{array}{l}\text { Finansial ibu dari anak dengan } \\
\text { autisme }\end{array}$ & Pokoknya keuangan tuh gak bisa mencukupi dia terapi disana \\
\hline & Kondisi fasilitas kesehatan & Ya alhamdulillah sih bagus.,cukup sih \\
\hline & Kondisi lingkungan rumah & $\begin{array}{l}\text { Kalau misalkan kita buat aman maksudnya nyaman dan aman rumah sih } \\
\text { nyaman-nyaman aja paling sih karena di jalan besar kadang-kadang } \\
\text { khawatirnya dia keluar gitu dalam segi keamanan gitu aja sih }\end{array}$ \\
\hline & $\begin{array}{l}\text { Cara mendapatkan informasi } \\
\text { mengenai autisme }\end{array}$ & $\begin{array}{l}\text { Ikutan seminar terus pelatihan, biasanya kan suka ada pelatihan ini disini tuh } \\
\text { biasanya ada pelatihan apa yang gratis ya disini bareng-bareng }\end{array}$ \\
\hline & $\begin{array}{l}\text { Hal baru yang dipelajari selama } \\
\text { merawat anak dengan autisme }\end{array}$ & $\begin{array}{l}\text { Cuman dia kalau ngerjain tugas harus ada reward meskipun cuman kue satu } \\
\text { diam au semangat dia ngeliat kue nya dulu }\end{array}$ \\
\hline & Rekreasi & $\begin{array}{l}\text { Suka dan sering diajak. Kalau ke Lembang di tempat rekreasi itu ada kelinci } \\
\text { atau kambing dia suka memberi makan }\end{array}$ \\
\hline & Transportasi & $\begin{array}{l}\text { Membantu sih pokoknya selama saya naik angkutan segala macam aman- } \\
\text { aman aja sih. }\end{array}$ \\
\hline
\end{tabular}

Psyche 165 Journal Vol.15 No. 1 (2022) 19-24 


\subsection{Kesehatan fisik}

Mengasuh dan merawat anak dengan gangguan spektrum autisme tidak berpengaruh terhadap aktivitas sehari-hari ibu. Pada penelitian ini ditemukan bahwa ibu dari anak dengan autisme masih memiliki waktu untuk melakukan hobi atau aktivitas yang disukai, mengerjakan tugas rumah tangga dan bertemu temanteman.

Ibu dari anak dengan autisme merasakan lelah yang disebabkan oleh perilaku anak yang sulit ditangani seperti berteriak dan berlarian. Pada situasi belajar, ibu juga perlu memberikan instruksi berkali-kali dan berulang. Hal tersebut membuat ibu merasakan jenuh dalam menghadapi anak dengan autisme. Ibu juga terkadang merasakan sakit badan, pegal-pegal bahkan pernah terluka dikarenakan anak tantrum. Kondisi tersebut membuat ibu berusaha mencari waktu untuk tetap beristirahat, menjaga pola makan serta berolahraga agar ibu tetap sehat dan memiliki kualitas tidur yang cukup.

\subsection{Psikologis}

Perasaan ibu pertama kali mendapatkan anaknya didiagnosa gangguan spektrum autisme berbeda-beda diantaranya, terkejut, bingung, sedih, marah pada Tuhan, ada penolakan dalam diri dan ada yang sudah menduga anaknya berkebutuhan khusus. Ibu juga merasakan kurang percaya diri. Namun setiap ibu berusaha menerima keadaan bahwa anaknya didiagnosis gangguan spektrum autisme. Saat proses penerimaan, ibu mencoba mencari informasi lebih dalam mengenai autisme, penanganan dan tempat terapi. Seiring berjalannya waktu, ibu berusaha mengambil hikmah dari kondisi yang mereka alami dan perlahan tumbuh rasa percaya diri memiliki anak dengan autisme.

Selama mengasuh anak dengan autisme muncul perasaan positif dan negatif. Perasaan positif yang dirasakan ibu adalah bersyukur dan senang saat anak memperlihatkan sedikit kemajuan dalam perkembangannya. Perasaan negatif yang dirasakan ibu adalah sedih, kesal dan khawatir. Kemudian keyakinan beragama berpengaruh pada pengasuhan anak dengan autisme. Ibu cenderung menjadi lebih dekat dengan Tuhan dan kualitas beragama meningkat.

Dari hasil penelitian ini juga ditemukan bahwa ibu masih memiliki waktu untuk merawat diri dan memperhatikan penampilan. Perlu adanya pendampingan peran dengan pasangan atau keluarga untuk menjaga anak dengan autisme di rumah saat ibu melakukan perawatan di luar rumah. Pada kemampuan belajar, mengingat dan konsentrasi ada ibu yang merasa sulit berkonsentrasi terhadap kegiatan yang dilakukan selama mengasuh anak dengan autisme namun ada yang tidak terpengaruh sama sekali.

\subsection{Relasi sosial}

Ibu dari anak dengan autisme merasakan pengaruh terhadap hubungan dengan keluarga, dimana ada anggota keluarga yang dapat menerima dan memahami kondisi anak namun ada satu ibu yang merasa keluarganya sulit menerima disebabkan tidak memahami autisme. Ibu merasa tidak dekat dengan tetangga. Relasi ibu dengan pasangan juga berpengaruh dimana menjadi kompak terutama berbagi peran dalam menjaga dan merawat anak dengan autisme. Namun pada penelitian ini ditemukan bahwa hubungan intim dengan pasangan menjadi berkurang. Hal tersebut disebabkan bukan hanya fokus mengasuh anak tetapi juga dipengaruhi oleh pekerjaan rumah tangga.

Ibu juga memperoleh dukungan dari beberapa sumber seperti keluarga, teman, dan teteangga. Mereka memberikan informasi mengenai sekolah dan tempat terapi. Keluarga juga membantu menjaga dan mengasuh anak dengan autisme saat ibu bepergian, serta memberikan bantuan materil untuk membeli alatalat terapi dan biaya terapi.

\subsection{Lingkungan}

Ibu memperoleh informasi mengenai autisme dari berbagai cara yaitu browsing internet, membaca literatur, menonton video di platform youtube, mendapatkan penjelasan dari psikolog dan dokter, bertukar pikiran dengan teman yang memiliki anak dengan autisme, mengikuti seminar serta pelatihan. Selain itu ibu juga mempelajari hal-hal baru seperti menerapkan reward, pengetahuan lebih banyak mengenai autisme, cara menghadapi dan mengajarkan anak dengan autisme.

Dalam mengasuh dan merawat anak dengan autisme diperlukan finansial untuk perawatan seperti sekolah, terapi dan makanan. Ibu cenderung merasa kondisi finansialnya belum dapat memenuhi berbagai terapi.

Hasil lainnya dari penelitian ini ditemukan gambaran fasilitas kesehatan, kenyamanan dan keamanan di lingkungan selama mengasuh anak dengan autisme sudah cukup memadai untuk diakses. Begitu juga transportasi yang digunakan khususnya untuk melakukan perawatan sudah cukup memadai baik transportasi umum maupun pribadi. Sebagian ibu menilai bahwa kondisi rumah mereka nyaman untuk tinggal. Namun ibu merasa khawatir saat anak bermain di lingkungan rumah dikarenakan takut jika anak tertabrak kendaraan atau kabur.

\section{Kesimpulan}

Kesimpulan yang didapat dari penelitian ini adalah ditemukan 22 tema dari hasil wawancara dengan 7 partisipan yang merupakan ibu dari anak dengan gangguan spektrum autisme. Tema yang ditemukan menggambarkan kualitas hidup pada ibu dari anak dengan gangguan spektrum autisme yang terdiri dari empat domain yaitu domain fisik, psikologis, relasi sosial dan lingkungan. Pada domain fisik, merawat 
anak dengan autisme tidak berpengaruh terhadap aktivitas sehari-hari. Ibu merasakan lelah fisik maupun psikis. Pada domain psikologis, setiap ibu merasakan berbagai perasaan saat mendengar pertama kali anak didiagnosa gangguan spektrum autisme. Selama mengasuh dan merawat anak dengan autisme muncul berbagai perasaan positif dan negatif. Selain itu keyakinan beragama ibu semakin meningkat. Ibu dari anak dengan autisme masih memiliki waktu untuk merawat dan memperhatikan penampilan mereka. Pada domain relasi sosial, ibu dari anak dengan autisme berpengaruh terhadap hubungan dengan keluarga, teman, tetangga dan pasangan. Ibu menjadi lebih kompak dengan pasangan terutama dalam berbagi peran merawat anak dengan autisme. Ibu dari anak dengan autisme juga memperoleh dukungan dari berbagai sumber yaitu keluarga, teman dan tetangga. Ibu merasa senang dan bersyukur memiliki orangorang terdekat yang memberikan dukungan selama mengasuh dan merawat anak dengan autisme. Pada domain lingkungan, ibu dari anak dengan autisme memiliki kebutuhan yang diperlukan bagi perawatan seperti melakukan berbagai terapi, sekolah dan makanan. Bagi ibu fasilitas yang dibutuhkan untuk anak dengan autisme sudah cukup memadai dan mudah untuk diakses mulai dari fasilitas kesehatan, dan transportasi.Begitu juga kondisi rumah dan fisik lingkungan ibu merasa sudah cukup memadai.

Keterbatasan dari penelitian ini hanya meneliti pada ibu dari anak dengan gangguan spektrum autisme. Pada penelitian selanjutnya diharapkan bisa melihat kualitas hidup bukan hanya dari ibu sebagai pengasuh utama melainkan dari ayah dari anak dengan gangguan spektrum autisme sehingga data yang diperoleh lebih komprehensif.

\section{Daftar Rujukan}

[1]. Mash, E.J., \& Wolfe, D.A. (2015). Abnormal Child Psychology. Wadsworth Publishing.

[2]. American Psychiatric Association. (2013). Diagnostic and Statistical Manual of Mental Disorder Fifth Edition. Washington, DC: American Psychiatric Publishing.

[3]. Centers for Disease Control and Prevention. (2020). Autism Spectrum Disorder (ASD) Data \& Statistics. Retrieved Maret 2020, from https://www.cdc.gov/ncbddd/autism/data.html.

[4]. Mitchell, S., Brian, J., Zwaigenbaum, L., Roberts, W., Szatmari, P., Smith, I., \& Bryson, S. (2006). Early language and communication development of infants later diagnosed with autism spectrum disorder. Journal of Developmental and Behavioral Pediatrics, 27(2 SUPPL. 2). https://doi.org/10.1097/00004703-200604002-00004

[5]. Challman, T. D., Barbaresi, W. J., Katusic, S. K., \& Weaver, A. (2003). The yield of the medical evaluation of children with pervasive developmental disorders. Journal of Autism and Developmental Disorders, 33(2), 187-192. https://doi.org/10.1023/A:1022995611730

[6]. Fombonne, E. (2003). Epidemiological surveys of autism and other pervasive developmental disorders: an update. Journal of Autism and Developmental Disorders, 33(4), 365-382. https://doi.org/10.1023/A:1025054610557
[7]. Dissanayake, C., \& Sigman, M. (2000). Attachment and emotional responsiveness in children with autism. International Review of Research in Mental Retardation, 23, 239-266. https://doi.org/10.1016/S0074-7750(00)80013-0

[8]. Atkinson, A. P. (2009). Impaired recognition of emotions from body movements is associated with elevated motion coherence thresholds in autism spectrum disorders. Neuropsychologia, $\quad 47(13), \quad 3023-3029$. https://doi.org/10.1016/J.NEUROPSYCHOLOGIA.2009.05.0 19

[9]. Ozturk, Y., Riccadonna, S., \& Venuti, Parenting dimensions in mothers and fathers of children with Autism Spectrum Disorders. Research in Autism Spectrum Disorders, 8(10), 1295-1306. https://doi.org/10.1016/j.rasd.2014.07.001

[10]. Hoefman, R., Payakachat, N., van Exel, J., Kuhlthau, K., Kovacs, E., Pyne, J., \& Tilford, J. M. (2014). Caring for a Child with Autism Spectrum Disorder and Parents' Quality of Life: Application of the CarerQol. Journal of Autism and Developmental Disorders, 44(8), 1933-1945. https://doi.org/10.1007/s10803-014-2066-1

[11]. Mansell, W., \& Morris, K. (2004). A survey of parents' reactions to the diagnosis of an autistic spectrum disorder by a local service. Autism, 8(4), 387-407. https://doi.org/10.1177/1362361304045213

[12]. Rapin, I. (2001). An 8-year-old boy with autism. Journal of the American Medical Association, 285(13), 1749-1757. https://doi.org/10.1001/jama.285.13.1749

[13]. Roberts, J. M. (2012). Notice to readers A Review of the Research to Identify the Most Effective Models of Best Practice in the Management of Children with Autism Spectrum Disorders Autism Treatment Review Centre for Developmental Disability Studies ii Autism Treatment Review.

[14]. Peacock, G., Amendah, D., Ouyang, L., \& Grosse, S. D. (2012). Autism spectrum disorders and health care expenditures: The effects of co-occurring conditions. Journal of Developmental and Behavioral Pediatrics, 33(1), 2-8. https://doi.org/10.1097/DBP.0b013e31823969de

[15]. Bromley, J., Hare, D. J., Davison, K., \& Emerson, E. (2004). Mothers supporting children with autistic spectrum disorders. Autism, 8(4), 409-423. https://doi.org/10.1177/1362361304047224

[16]. Hamlyn-Wright, S., Draghi-Lorenz, R., \& Ellis, J. (2007). Locus of control fails to mediate between stress and anxiety and depression in parents of children with a developmental $\begin{array}{llll}\text { disorder. } & \text { Autism, } & \text { 41(6), }\end{array}$ https://doi.org/10.1177/1362361307083258

[17]. Kuhlthau, K., Payakachat, N., Delahaye, J., Hurson, J., Pyne, J. M., Kovacs, E., \& Tilford, J. M. (2014). Quality of life for parents of children with autism spectrum disorders. Research in Autism Spectrum Disorders, 8(10), 1339-1350. https://doi.org/10.1016/j.rasd.2014.07.002

[18]. Benderix, Y., \& Sivberg, B. (2007). Siblings' Experiences of Having a Brother or Sister With Autism and Mental Retardation: A Case Study of 14 Siblings From Five Families. Journal of Pediatric Nursing, 22(5), 410-418. https://doi.org/10.1016/j.pedn.2007.08.013

[19]. Baker-Ericzén, M. J., Brookman-Frazee, L., \& Stahmer, A (2005). Stress Levels and Adaptability in Parents of Toddlers with and without Autism Spectrum Disorders. Research and Practice for Persons with Severe Disabilities, 30(4), 194204. https://doi.org/10.2511/rpsd.30.4.1

[20]. World Health Organization. (1996). Introduction, Administration, Scoring and Generic Version of The Assessment. 
[21]. Creswell, J. W., \& Creswell, J. D. (2018). Research Design [22]. Castillo-Montoya, M. (2016). Preparing for Interview Qualitative, Quantitative, and Mixed Method Approaches: Fifth Edition. SAGE Publishing.

Research: The Interview Protocol Refinement Framework.

The Qualitative Report, 21(5), 5-6.

https://doi.org/10.46743/2160-3715/2016.2337 